\title{
Constant Infusion of Hypertonic Saline in the Dog
}

\section{The Relative Importance of Plasma Na Concentration and GFR as the Determinants of Renal Na Excretion}

\author{
Masahito Nagasaka, M.D., Kazumichi Nakamura, M.D., Takashi \\ Kinouchi, M.D., Teizo Ito, M.D., Masao Takahashi, M.D., \\ and Yawara Yoshitoshi, M.D.
}

\section{SUMMARY}

Renal $\mathrm{Na}$ excretion correlated well with the product of elevation in plasma Na concentration from original value and GFR, as was suspected from the kinetic model. This was found to be true in the control hypertonic saline diuresis and in the physiologic saline preloading experiment. However, in experiment with aortic constriction correlation was unsatisfactory.

Relative importance of elevation in plasma $\mathrm{Na}$ concentration and GFR was estimated by multiple regression analysis. Their importance was similar and original regression equation was verified in the control and the saline preloading experiment. However, in the aortic constriction experiment, while weight for elevation of plasma $\mathrm{Na}$ concentration remained unchanged, that for GFR was almost eliminated. This finding may be to explain the reported irrelevance of GFR to renal $\mathrm{Na}$ excretion during massive saline diuresis. It is postulated that manipulation of large artery system is the cause of this apparent irrelevance. Further, when GFR was reduced drastically by aortic constriction, renal $\mathrm{Na}$ excretion was again larger than was predicted by the regression equation with small coefficient for GFR.

\section{Additional Indexing Words :}

Saline preloading Aortic constriction Na regulatory system

$\mathrm{I}^{\mathrm{N}}$ the previous studies it is demonstrated that renal $\mathrm{Na}$ excretion $\left(\mathrm{E}_{\mathrm{Na}}\right)$ is apparently dependent on the plasma $\mathrm{Na}$ concentration $\left(\mathrm{P}_{\mathrm{Na}}\right)$ during and after the constant infusion of hypertonic saline in the dog. ${ }^{1-4)}$ In one previous report it is also concluded that glomerular filtration rate (GFR) has little influence on the Na excretion, when GFR is reduced by inflating a balloon in the aorta so long as it remains above $50 \%$ of control value. ${ }^{4}$ In the classical theory of glomerulo-tubular balance, GFR should have important role in determining the renal $\mathrm{Na}$ excretion when it varies.5) In a kinetic model of

From the First Department of Medicine, Faculty of Medicine, University of Tokyo, Tokyo.

Received for publication March 24, 1970. 
the first report, GFR must also have its own influence on urinary $\mathrm{Na}$ output, since GFR is adopted rather than Na conductance in the more complex model. ${ }^{1)}$ So, it is decided here to estimate the role of GFR in renal $\mathrm{Na}$ excretion and its relative importance compared with that of plasma $\mathrm{Na}$ concentration during hypertonic saline diuresis and also in its various experimental modifications.

\section{Methods}

The experimental data are collected from all of the previous studies, namely, renal $\mathrm{Na}$ excretion rate and plasma $\mathrm{Na}$ concentration during and after constant infusion of $100 \mathrm{ml}$. of $10 \% \mathrm{NaCl}$ solution, ${ }^{1}$ during hypertonic saline diuresis after physiologic saline preloading (some with aldosterone pretreatment), ${ }^{3}$ and the same under aortic constriction by a balloon catheter. ${ }^{4)}$ GFR is estimated from endogenous creatinine clearance.

Statistical procedures. $\Delta \mathrm{P}_{\mathrm{Na}}$ is estimated as the elevation of plasma $\mathrm{Na}$ concentration above the concentration just before the beginning of constant infusion. $\Delta \mathrm{P}_{\mathrm{Na}} \cdot \mathrm{GFR}$ is calculated as the product of $\Delta \mathrm{P}_{\mathrm{Na}}$ and GFR. Correlations and regressions are analyzed as usual between $\mathrm{E}_{\mathrm{Na}}$ and $\Delta \mathrm{P}_{\mathrm{Na}}, \mathrm{GFR}$, and $\Delta \mathrm{P}_{\mathrm{Na}} \cdot \mathrm{GFR}$. Finally, multiple regression is computed for $\log \mathrm{E}_{\mathrm{Na}}, \log \Delta \mathrm{P}_{\mathrm{Na}}$, and $\log$ GFR by OKITAC at the Data Processing Center of the University of Tokyo.

\section{Results}

In the first report of the present series, it was demonstrated that during the diuresis induced by hypertonic saline infusion there was a definite correlation between $\Delta \mathrm{P}_{\mathrm{Na}}$ and $\mathrm{E}_{\mathrm{Na}}{ }^{1}$ ) and the correlation coefficient was calculated to be 0.54 (Fig. 1). The correlation coefficient between GFR and $\mathrm{E}_{\mathrm{Na}}$ was calculated now in the three from the control experiments (on a same $\operatorname{dog} G$ ), whcre GFR was measured by creatinine clearance, and it was 0.72 omitting

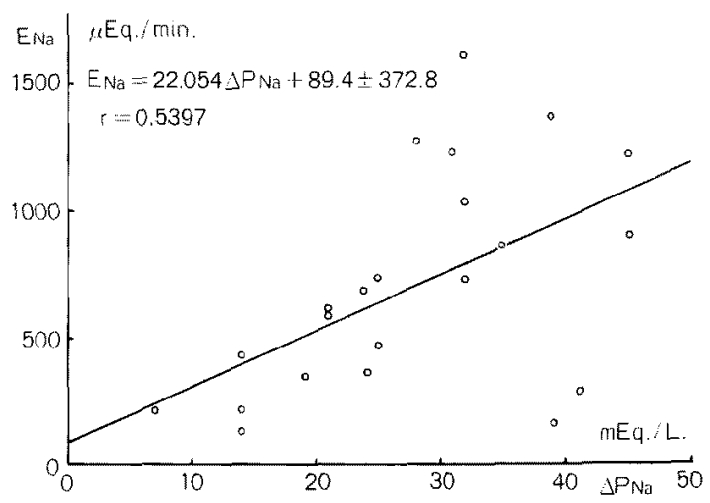

Fig. 1. Relationship between $\Delta \mathrm{P}_{\mathrm{Na}}$ and $\mathrm{E}_{\mathrm{Na}}$ in the control experiment. Straight line is the regression line. 


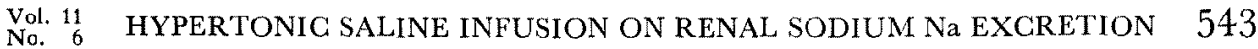

2 points (Fig. 2). According to the kinetic model used heretofore throughout the study, ${ }^{11}$ the product $\Delta \mathrm{P}_{\mathrm{Na}}$. GFR comprises filtered overload to the renal tubules. So, in order to estimate the relevance of the filtered overload to urinary $\mathrm{Na}$ excretion, the correlation between $\Delta \mathrm{P}_{\mathrm{Na}}$. GFR and $\mathrm{E}_{\mathrm{Na}}$ was calculated, and it was 0.85 (Fig. 3). It is apparent from those figures that the fitness improved considerably by including GFR as a factor in addition to $\mathrm{P}_{\mathrm{Na}}$. The regression equation derived for the last relationship became as follows :

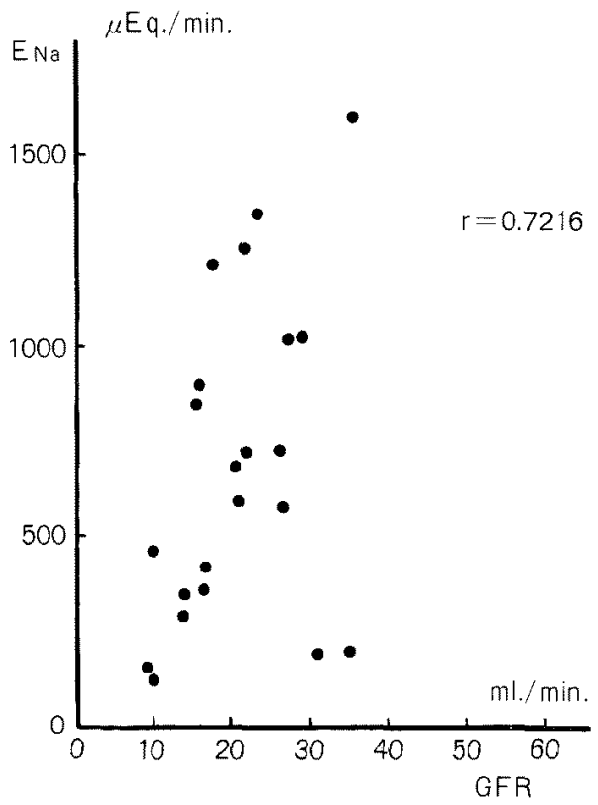

Fig. 2. Relationship between GFR and $\mathbf{E}_{\mathrm{N} a}$.

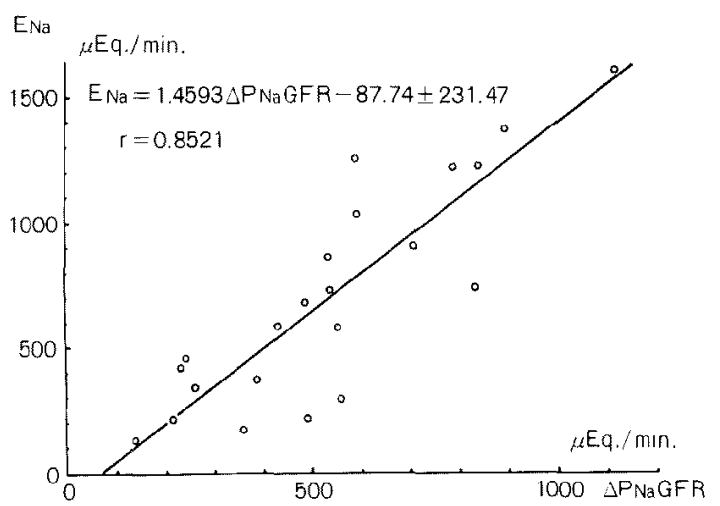

Fig. 3. Relationship between $\Delta \mathrm{P}_{\mathrm{Na}} \cdot \mathrm{GFR}$ and $\mathrm{E}_{\mathrm{Na}}$. Straightline is the regression line. 


$$
\mathrm{E}_{\mathrm{Na}}=\mathrm{K} \cdot \Delta \mathrm{P}_{\mathrm{Na}} \cdot \mathrm{GFR}+\mathrm{b} \pm \mathrm{e},
$$

and the constant $\mathrm{K}$ modifying $\Delta \mathrm{P}_{\mathrm{Na}}$. GFR in the equation was 1.46 . Since in the previous report GFR was measured as an average throughout the experiment so as to compare it with $\mathrm{Na}$ conductance, the ratio between these 2 parameters in the control experiments was 1.78 , and it is different from the value of $\mathrm{K}$ obtained by the present calculation in which GFR was determined for each urinary collection period.

In the third paper dealing with physiologic saline preloading, ${ }^{3)}$ the tendency for improvement was the same as was seen in Fig. 5 compared with Fig. 4. The ratio between $\mathrm{Na}$ conductance and GFR was 1.12 and $\mathrm{K}$ in the regression equation was 1.57 . It is interesting to note here that, while the ratios obtained from the 2 different experiments diverged, the K's were

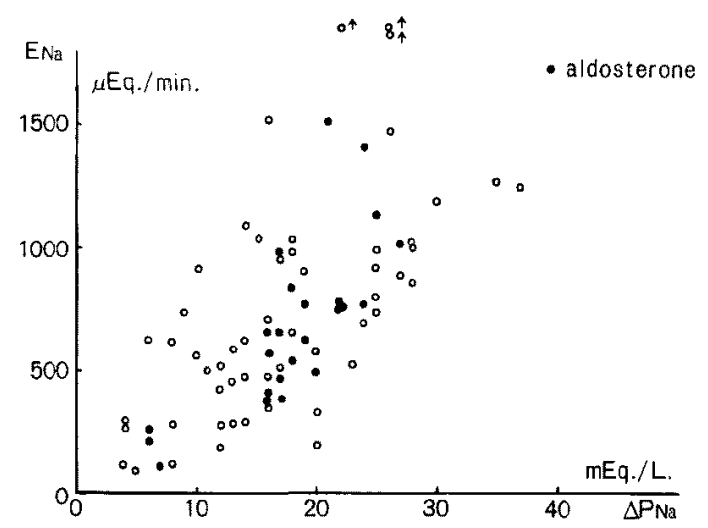

Fig. 4. Relationship between $\Delta \mathrm{P}_{\mathrm{Na}}$ and $\mathrm{E}_{\mathrm{Na}}$ in the physiologic saline preloading experiment. Solid circles are the points for aldosterone pretreatment group.

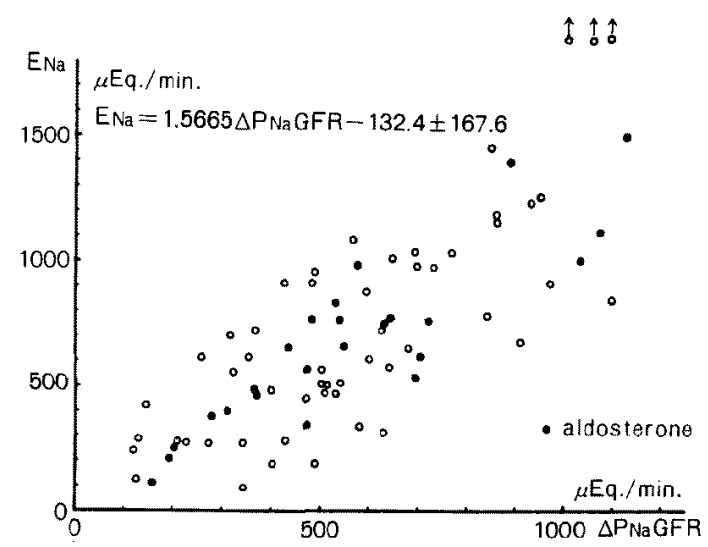

Fig. 5. Relationship between $\Delta \mathrm{P}_{\mathrm{Na}} \cdot \mathrm{GFR}$ and $\mathrm{E}_{\mathrm{Na}}$. Solid circles are the points for aldosterone pretreatment group. 
approaching each other which were statistically indistinguishable. In Fig. 4 and 5, points for aldosterone pretreatment were also plotted, and they have no particularity among those of simple preloading experiment. In the fourth article in which reduction in GFR was effected by aortic constriction, ${ }^{4}$ the inclusion of GFR as a factor besides $\Delta \mathrm{P}_{\mathrm{Na}}$ did not improve the regression of $\mathrm{E}_{\mathrm{Na}}$ as in the previous occasions (Fig. 6 and 7). Therefore, it may be concluded that there remains some unknown factor(s) operating in this case in the determination of $\mathrm{E}_{\mathrm{Na}}$.

Above considerations were summarized in Fig. 8. Two parameters, K and $b$, were much alike in the control and saline-preloaded experiments, but those of the aorta-constricted experiment were largely deviated. Here, only a smaller fraction of altered overload was excreted when it increased, and there

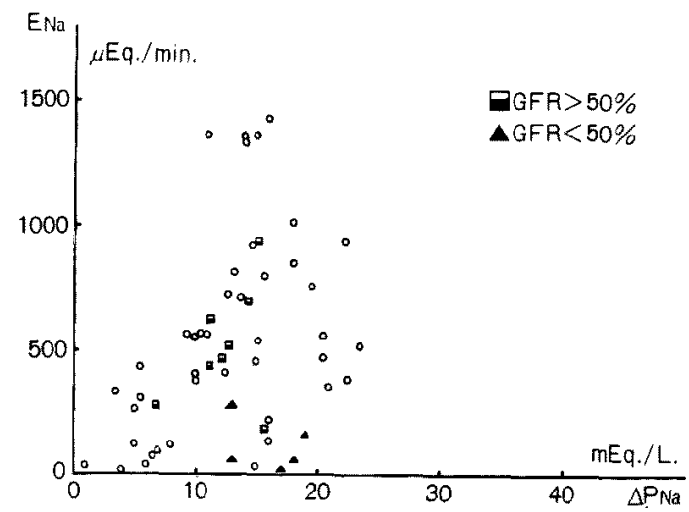

Fig. 6. Relationship between $\Delta \mathrm{P}_{\mathrm{Na}}$ and $\mathrm{E}_{\mathrm{Na}}$ in the aortic constriction experiment. Semisolid squares are points during aortic constriction with GFR above $50 \%$ of control period. Solid pyramids are points with GFR below $50 \%$.

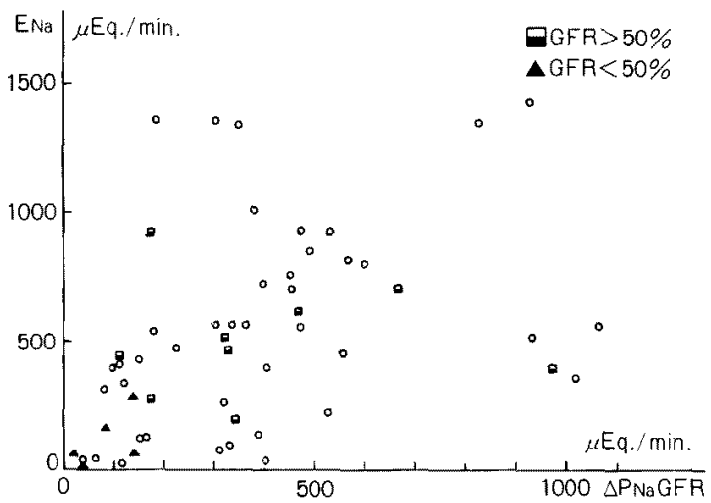

Fig. 7. Relationship between $\Delta \mathrm{P}_{\mathrm{Na}} \cdot \mathrm{GFR}$ and $\mathrm{E}_{\mathrm{NR}}$. Semisolid squares and solid pyramids are as same as in Fig. 6. 
existed a considerable moiety of $\mathrm{E}_{\mathrm{Na}}$ as a constant fraction. Finally, error terms were smaller in the first 2 groups compared with that of regression based only on $\mathrm{P}_{\mathrm{Na}}$ (dotted bar). However, in the aortic constriction experiment it became large again.

In order to estimate the validity of the above analysis, the relative importance of the 2 factors, $\Delta \mathrm{P}_{\mathrm{Na}}$ and GFR, were weighed subsequently by multiple regression technique. The original equation was transformed into logarithmic style :

$$
\log \mathrm{E}_{\mathrm{Na}}=\beta_{0}+\beta_{1} \log \Delta \mathrm{P}_{\mathrm{Na}}+\beta_{2} \log \mathrm{GFR} \pm \mathrm{e},
$$

where $\beta_{0}$ corresponds to $\log \mathrm{K}$ and the constant term $\mathrm{b}$ was ignored. $\beta_{1}$ and $\beta_{2}$ were thought to represent weights. The results were shown in Fig. 9 . By inspection it was immediately apparent that parameters for control and saline preloading experiments were identical here again. In aortic constriction experiment, the weight of GFR was almost zero although the weight of $\Delta \mathrm{P}_{\mathrm{Na}}$ was near one and not different from control.

From above computations, it was confirmed morcover that the first nonlogarithmic equation was appropriate, since both coefficients $\beta_{1}$ and $\beta_{2}$ were very near to unity. The relative importance of $\Delta \mathrm{P}_{\mathrm{Na}}$ and GFR were similar just as anticipated from the kinetic model. In the aortic constriction experiment, however, the influence of GFR was eliminated with catheterization alone and before inflation of balloon. So it is suspected that the manipulation of large artery system is sufficient to cause this alteration in Na regulatory system. Lastly, $\mathrm{E}_{\mathrm{Na}}$ at the time of GFR reduction was calculated by the

$$
E_{N a}=K \cdot \Delta P N a \cdot G F R+b \pm e
$$

k

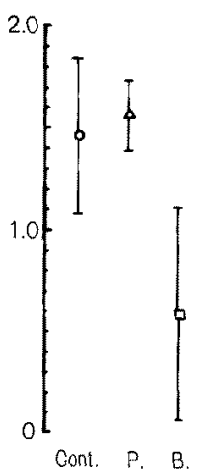

b

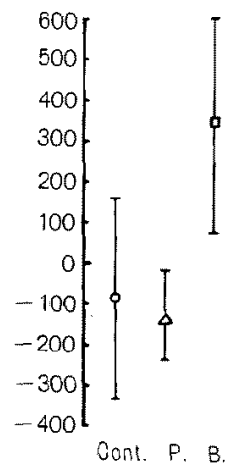

e

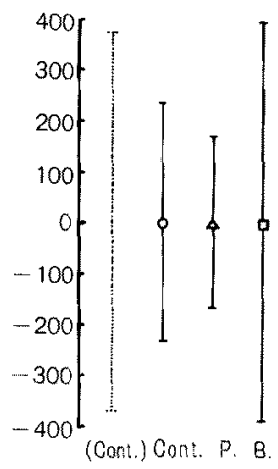

Fig. 8. Graphic representation of parameters in the regression equation at the top of the figure. Cont.: Control, P.: Preloading, and B.: Ballooning. Bars are the range of $95 \%$ confidence. Dotted line is presented as a comparison and for the regression equation basing on $\Delta \mathrm{P}_{\mathrm{Na}}$ only. 


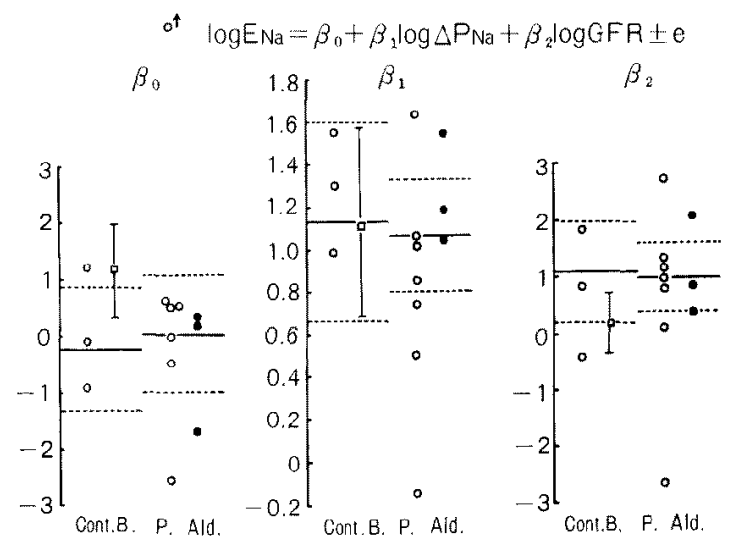

Fig. 9. Graphic representation of parameters in the regression equation at the top of the figure. Cont.: Control, B.: Ballooning, P.: Preloading, and Ald.: Aldosterone. Solid lines are parameters for pooled data and dotted lines are the range of $95 \%$ confidence. Open circles are values for individual experiments. Open squares with bars are for ballooning experiment with the confidence range. Solid circles are values for individual experiments with aldosterone.

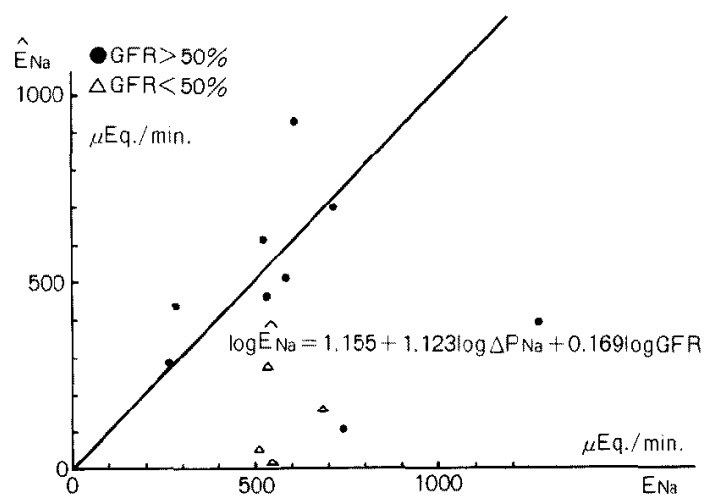

Fig. 10. Actual and estimated $\mathrm{E}_{\mathrm{Na}}$ during aortic constriction. Solid circles are points for GFR larger than $50 \%$ of control period, and open pyramids are for GFR smaller than $50 \%$.

computed regression equation and it was compared with the values actually observed (Fig. 10). It was demonstrated that when the GFR reduction was mild (above $50 \%$ of control period) those values almost coincided, whereas if the reduction was drastic (below $50 \%$ ) $\mathrm{E}_{\mathrm{Na}}$ was greater than predicted. It seemed that there existed a mechanism to maintain $\mathrm{E}_{\mathrm{Na}}$ in the face of acute reduction of GFR by experimental procedure. 


\section{Discussion}

In a previous report, the role of GFR in the determination of renal $\mathrm{Na}$ excretion was discussed historically. ${ }^{4)}$ In brief, Wesson and Smith have formulated their model as $\mathrm{Na}$ excretion was influenced by both GFR and tubular reabsorption. ${ }^{5}$ They also made regression analysis and delineated GFR as a primary variable. Later, Wesson adopted a non-linear relationship between $\mathrm{Cl}$ excretion and GFR in a wider range of variation in GFR. ${ }^{6,7)}$ However, other authors sometimes favored filtered load as a determinant rather than GFR itself. Filtered load as a product of $P_{\mathrm{Na}_{\mathrm{a}}}$ and GFR is largely dependent on the change in GFR because of small variability in $\mathrm{P}_{\mathrm{Na}}$ at ordinary situations.

The present study designated $A \mathrm{P}_{\mathrm{Na}}$ and GFR as equally contributing factors to $\mathrm{E}_{\mathrm{Na}}$. Na conductance in the simple model can be re-defined now as a value 1.5 times larger than GFR. Since $\mathrm{K}$ was not unity, $r$ in the complex model should be determined again in a manner like in the first paper. ${ }^{1)}$ However, that simple model is satisfactory in approximation was demonstrated in the second report. ${ }^{2}$ The only modification would be that $\mathrm{Na}$ conductance is better fitted when it is made to vary with GFR. In a similar experiment with hypertonic saline infusion by Levy and Ankeney, the tubular reabsorptive mass of $\mathrm{Na}$ increased or decreased with GFR in the same direction. ${ }^{8)}$ Since $\mathrm{Na}$ reabsorption in the present model is near to the product of threshold $\mathbf{P}_{\mathrm{Na}}$ and GFR, their results are likely to contend $\mathrm{K}$ to be around unity.

That the reduction in the renal perfusion pressure would effect the decreased urine flow was first observed by Goll.91 Since then it was believed to be obvious that glomerular filtration would affect the urinary excretion at large. However, de Wardener et al. initiated the idea that during volume expansion by saline infusion $\mathrm{E}_{\mathrm{Na}}$ persists independently of the reduction in GFR. 10),11) This was the hint for the concept of Na conductance in the present series. The fourth report of the series demonstrated this to be the fact as well.4) However, the present computation invoked GFR as a determining factor once again. The discrepancy may be explained by the consideration that various procedures used to reduce GFR would often include the manipulation of the large artery system, and this might cause the irrelevance of GFR to $\mathrm{E}_{\mathrm{Na}}$ during saline diuresis. It will be needed to mention here the result of Blythe and Welt that during the hypertonic saline infusion with the reduction of GFR by vena cava occlusion $\Delta \mathrm{P}_{\mathrm{Na}}$ and $\log \mathrm{E}_{\mathrm{Na}}$ were found to be well linear. ${ }^{12)}$ They put whole experimental points on a same chart. When only points of control period are re-plotted omitting those during occlusion, the relationship between $\Delta \mathrm{P}_{\mathrm{Na}}$ and $\mathrm{E}_{\mathrm{Na}}$ becomes again linear and not log-linear. 


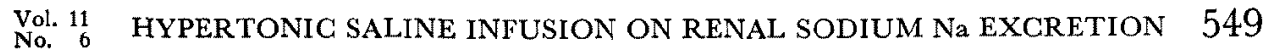

Their protocol can be used to confirm the present theory in spite of their original contention.

Recently, micropuncture studies on single nephrons revised the older glomerulo-tubular balance theory and advanced the more subtle observations. The München group asserted, particularly, that variations in arterial pressure within the renal autoregularoty range and/or spontaneous fluctuations in GFR did not affect the glomerulo-tubular balance in the proximal tubule, ${ }^{12)-15}$ but that reduction in GFR by arterial clamping did alter the balance. ${ }^{16)}$ The present result is in good accord with their findings. $\mathbf{E}_{\mathrm{Na}}$ became little affected by variations in GFR when it was reduced by manipulation of large artery system.

In conclusion, it may be said that following arterial catheterization the influence of GFR on $\mathrm{E}_{\mathrm{Na}}$ is minimized (Fig. 3 in ref. 4), and further when GFR is reduced drastically by inflating a balloon in the aorta $\mathrm{E}_{\mathrm{Na}}$ is still larger than is predicted by the regression equation with already minimized influence of GFR on $\mathrm{E}_{\mathrm{Na}}$. This may comprise the apparent compensation phenomenon in renal $\mathrm{Na}$ excretion during hypertonic saline diuresis despite artificial reduction of GFR.

\section{REFERENCES}

1. Nagasaka, M., Nakamura, K., Kinouchi, T., Ito, T., Takahashi, M., and Yoshitoshi, Y.: Jap. Heart J. $9: 281,1968$.

2. Kinouchi, T., Nakamura, K., Ito, T., Nagasaka, M., Takahashi, M., and Yoshitoshi, Y.: Jap. Heart J. $10: 335,1969$.

3. Nagasaka, M., Nakamura, K., Kinouchi, T., Ito, T., Takahashi, M., and Yoshitoshi, Y.: Jap. Heart J. 10: 428, 1969.

4. Nakamura, K., Kinouchi, T., Ito, T., Nagasaka, M., Takahashi, M., and Yoshitoshi, Y.: Jap. Heart J. 11: 533, 1970.

5. Smith, H. W.: Principles of Renal Physiology, New York, 1956.

6. Wesson L. G.: Medicine 36: 2811957.

7. Wesson, L. G.: Physiology of the Human Kidney, New York, 1969.

8. Levy, M. N. and Ankeney, J. L.: Proc. Soc. Exp. Biol. Med. 79: 491, 1952.

9. Goll, F. G.: Z. Rat. Med., N. F. 4: 78, 1854.

10. de Wardener, H.E., Mills, I. H., Glapham, W. F., and Hayter, C. J.: Clin. Sc. 21 : 249, 1961.

11. Mills, I. H., de Wardener, H. E., Hayter, C. J., and Clapham, W. F.: Clin. Sc. 21: 259, 1961.

12. Blythe, W. B. and Welt, L. G.: J. Clin. Invest. 42: 1491, 1963.

13. Liebau, G., Levine, D. Z., and Thurau, K.: Pfüg. Arch. 304: 57, 1968.

14. Levine, D. Z., Liebau, G., Fischbach, H., and Thurau, K.: Pflug. Arch. 304: 365, 1968.

15. Schnermann, J., Wahl, M., Liebau, G., and Fischbach, H.; Pflüg. Arch. 304: 90, 1968.

16. Wahl, M., Liebau, G., Fischbach, H., and Schnermann, J.: Pflüg. Arch. 304: 297, 1968. 